\title{
Resenhas
}

\section{GALVES, Charlotte; KATO, Mary; ROBERTS, Ian. 2019. Português brasileiro. Uma segunda viagem diacrônica. Campinas. Editora da Unicamp. 357p. ISBN 978-85-268-1485-1.}

\author{
Por/By: Carlos Felipe Pinto ${ }^{1,2}$
}

Palavras-chave: Português brasileiro; Gramática Gerativa; Linguística Histórica.

Keywords: Brazilian Portuguese; Generative Grammar; Historical Linguistics.

\section{Contextualização}

Português brasileiro. Uma viagem diacrônica (Roberts e Kato 1993) representou um grande avanço no âmbito da Linguística Histórica no Brasil porque reuniu trabalhos que discutiram as diferenças paramétricas que separam o $\mathrm{PB}^{3}$ do final do século $\mathrm{XX}$ do $\mathrm{PB}$ dos séculos XVIII-XIX e do PE atual. A obra, realizada em homenagem a

1. Professor Adjunto da Universidade Federal da Bahia. Programa de Pós-Graduação em Língua e Cultura. Salvador, Bahia - Brasil. https://orcid.org/0000-0002-4322-0199. E-mail: cfcpinto@gmail.com.

2. Bolsista do Programa Nacional de Pós-Doutorado (CAPES) de 01/04/2019 a 31/03/2020 no Programa de Pós-Graduação em Linguística da Universidade Estadual de Campinas. 3. Assumirei as já conhecidas siglas PB e PE para me referir ao português brasileiro e português europeu respectivamente. 
Fernando Tarallo, falecido prematuramente, possui 425 páginas, tem 12 capítulos, um prefácio e um posfácio, e pretendeu escrutinar propriedades gramaticais do PB a partir do casamento entre sociolinguistica variacionista e gramática gerativa, iniciado por Tarallo e Kato (1989), acompanhado por Charlotte Galves e um grupo de pós-graduandos, especialmente da Universidade Estadual de Campinas.

Depois de 26 anos, Português brasileiro. Uma segunda viagem diacrônica (Galves, Kato e Roberts 2019) atualiza questões presentes na primeira viagem, sobre a história gramatical do PB. A obra contém 11 capítulos, um prefácio e um posfácio, distribuídos em 357 páginas, que colocam em evidência a produtividade da agenda de pesquisa que fora inaugurada nos anos 1990. A obra é dedicada a Ilza Ribeiro, que também integrava o grupo, infelizmente falecida em fevereiro de 2017.

\section{Apresentação ${ }^{4}$}

No Prefácio (p.7-18), Charlotte Galves e Mary Kato contextualizam a obra a partir dos desenvolvimentos das pesquisas realizadas durante os 25 anos que a separam da primeira viagem diacrônica. As autoras apresentam de maneira clara os capítulos que compõem a coletânea e terminam lamentando a ausência de Ilza Ribeiro reconhecendo a importância de seus trabalhos como fonte de dados para muitos dos textos da coleção.

Ian Roberts, em Gramáticas "marginais" e mudanças sintáticas "extremas": O inglês e o português brasileiro (p. 23-56), discute se as mudanças linguísticas ocorridas no inglês e no PB são decorrentes de alterações endógenas ou do contato linguístico. Apresenta uma série de propriedades discutidas desde os anos 1980 para compreensão da variação paramétrica para mostrar que as duas línguas se opõem tanto às suas "parentes" atuais como aos seus "ancestrais". Sobre o inglês, parte do fato que o inglês antigo era uma língua como o germânico ocidental, o inglês médio como o islandês atual e o inglês atual não

4. Por razões de espaço, não se citarão textos discutidos nos capítulos, mesmo que se apresentem os diversos posicionamentos trazidos pelos autores para fundamentar suas discussões. 
se parece a nenhuma língua conhecida. Revisa a história do inglês, apontando que a Britânia, uma ilha céltico-romana, foi invadida por anglo-saxões (século V), por escandinavos (século VIII) e por normandos (século XI). Entre 1066 e 1132, nenhum texto em inglês sobreviveu, tendo o inglês médio ressurgido no século XII de forma bem diferente do inglês antigo. As hipóteses para seu surgimento são a versão tradicional, que propõe que o inglês foi altamente influenciado pela língua escandinava com a qual esteve em contato (caracterizando empréstimos), e uma proposta nova de que o inglês médio teria sido descendente de uma língua escandinava anglicizada (caracterizando mudança de língua). Analisa minuciosamente a proposta alternativa mas assume a tradicional, propondo que as causas da anomalia do inglês moderno são endógenas uma vez que as mudanças que transformaram o inglês aconteceram muito depois do contato com os escandinavos e foi decorrente de uma mudança em cascata ou, caso se leve em conta o contato linguístico, deve ser considerado o contato com os celtas, que chegaram à Inglaterra muito antes dos germanos. Sobre o PB, apresenta um conjunto de doze propriedades que o colocam como uma língua anômala em relação às demais línguas românicas. Sete podem ser atribuídas à perda da concordância, especialmente à marcação de pessoa, e as cinco demais são atribuídas ao contato com as línguas Bantu. Roberts faz alguma consideração sobre tipos de parâmetros e conclui que ambas as línguas foram transplantadas e entraram em contato com populações que já habitavam ou viriam a habitar as regiões a que chegaram. A conclusão é que o empréstimo de valores paramétricos pode tornar uma língua anômala à sua família bem como a sucessiva alteração de meso e microparâmetros em efeito de cascata pode levar a resultados superficialmente similares.

Juanito Ornelas de Avelar, em Sobre o papel do contato linguístico nas origens do português brasileiro (p. 57-91), examina fenômenos relacionados com a posição de sujeito que evidenciam uma influência africana na configuração do PB. Apresenta as principais hipóteses de formação do PB (deriva secular e contato linguístico) assumindo a posição de que os contatos com as línguas africanas são, de fato, o elemento que configurou a gramática do $\mathrm{PB}$ e das variedades africanas do português de maneira diferente do PE. A hipótese defendida é sustentada a partir de dados histórico-demográficos e linguísticos. São analisados três grupos de fenômenos linguísticos: a simplificação do 
paradigma flexional e as mudanças relacionadas ao parâmetro pro-drop; o aparecimento de constituintes inusitados em posição de sujeito; a interpretação existencial de orações com verbo "ter". A metodologia é bastante interessante porque compara os dados do PB com dados de variedades africanas do português mostrando que as estruturas discutidas são gramaticais em línguas africanas mas agramaticais no PE. Avelar conclui que o contato pode ter desencadeado as mudanças estudadas através de um processo de aquisição do português como L2.

Maria Eugênia Lammoglia Duarte, em O sujeito nulo referencial no português brasileiro e no português europeu (p. 93-126), recapitula 25 anos de estudo sobre a expressão e a omissão do sujeito pronominal no PB e PE, fazendo uma breve discussão sobre a relação entre simplificação do paradigma flexional e a inserção de "você" e "a gente" no sistema pronominal brasileiro como gatilhos para o incremento do uso de pronomes e conclui que a perda da flexão é anterior à entrada dos novos pronomes e, portanto, os novos pronomes não teriam sido a única causa da mudança no paradigma verbal. Apresenta resultados de trabalhos anteriores no sentido de que tanto os trabalhos realizados sob a perspectiva da mudança em tempo real (comparando falantes do século XIX com falantes do final do século XX) como na perspectiva da mudança em tempo aparente (comparando falantes mais velhos com mais novos), os estudos mostram que houve um decréscimo no preenchimento do sujeito. A assimetria entre primeira/segunda pessoas e terceira pessoa mostra que as primeira/segunda pessoas estão num estado muito mais avançado de preenchimento que a terceira, que, embora apareça mais preenchida que no século XIX, ainda apresenta razoável ocorrência nula. A análise do processo de mudança destaca o papel dos padrões sentenciais (com destaque para a função do antecedente na mudança) e o feixe de traços semânticos do referente de $3^{\mathrm{a}}$ pessoa e conclui que o PE, embora uma língua de sujeito nulo consistente, não tem um comportamento das línguas românicas de sujeito nulo prototípicas, como o italiano, uma vez que exibe raríssimos casos de pronomes pessoais com o traço [-animado] e que o $\mathrm{PB}$ ainda não é uma língua de sujeito expresso obrigatório mas também não pode ser comparado exatamente com as línguas de sujeito nulo parcial já que apresenta um claro movimento em direção aos pronomes expressos e menos restrições do que as chamadas línguas de sujeito nulo parcial. 
Charlotte Galves, em Revisitando a concordância no português brasileiro (p. 127-150), discute, em termos abstratos, como o enfraquecimento da concordância pode ser o responsável por uma série de propriedades superficiais encontradas no PB. Revisa sua proposta na "primeira viagem" discutindo que o decréscimo na frequência de sujeitos realizados, a fixação da ordem SVO, a ausência de subida de clíticos e a diminuição na concordância com estruturas com "se" estão relacionados com a mudança no paradigma verbal no português que opõe $1^{\mathrm{a}}$ pessoa a todas as demais, gerando apenas quatro combinações: [ \pm pessoa; \pm plural]. Trazendo à baila transformações no modelo gerativista, explica que a alteração paramétrica se deu na categoria AgrP, que, no PB, passou a ser uma posição-A' sustentando sua proposta no emparelhamento de seus resultados com os de outros pesquisadores, que olham para outros fenômenos mas chegam às mesmas conclusões sobre a natureza A' de AgrP no PB. Como, no Programa Minimalista, AgrP é eliminado, Galves pondera sobre duas análises para o sujeito nulo do PB com base na projeção apenas de TP: a primeira, com duas subpropostas, considera o sujeito nulo como resultado de movimento; a segunda considera o sujeito nulo ainda uma categoria vazia pro; contudo, os traços de $\mathrm{T}$ seriam os responsáveis pelas diferenças entre as línguas de sujeito nulo consistentes e as línguas de sujeito nulo parcial. Galves indica que, independentemente de qualquer que seja a escolha, os sujeitos em PB, estão numa posição-A'. O último aspecto discutido é a variação na realização da concordância verbal, argumentando que a variação na concordância verbal não seria um reflexo da coexistência de duas gramáticas, mas um reflexo de duas relações possíveis entre os traços dos núcleos $\mathrm{C} \mathrm{e} \mathrm{T,} \mathrm{uma} \mathrm{gerando} \mathrm{concordância} \mathrm{e} \mathrm{outra} \mathrm{não.} \mathrm{As}$ conclusões discutem a relação entre morfologia, sintaxe e aquisição e indicam que a morfologia não é a causa das mudanças sintáticas, mas, pelo contrário, seu reflexo.

Jairo Nunes, em Clíticos acusativos de terceira pessoa em português brasileiro como concordância de objeto (p. 151-172), discute o estatuto dos clíticos acusativos de terceira pessoa (ClA3P) no PB considerando sua assimetria tanto com os clíticos de primeira e segunda pessoa (onde os C1A3P só são adquiridos via escolarização enquanto os demais são adquiridos naturalmente na infância) como com os ClA3P no $\mathrm{PE}$ (onde os ClA3P são adquiridos naturalmente na infância como os demais). Assume a hipótese de que os ClA3P são, na gramática do 
falante escolarizado, marcas de concordância com o objeto no PB. Para sustentar sua hipótese, apresenta uma série de contrastes entre os clíticos com verbos finitos e não finitos mostrando que clíticos de primeira $\mathrm{e}$ segunda pessoa podem aparecer com qualquer forma verbal, mas os ClA3P aparecem apenas com formas que possuem flexão (ou seja, não podem aparecer com gerúndio e particípio em ênclise ou próclise), o que evidencia seu caráter de marcador de concordância. Nesse ponto, faz uma série de contrastes entre orações finitas e não finitas mostrando que, se a forma admite flexão, o ClA3P só aparece enclítico caso não haja flexão de sujeito. Caso contrário, o clítico aparece proclítico. Nunes dá evidências independentes para sua proposta discutindo o contraste entre infinitivo flexionado/não flexionado e uso de formas do futuro do subjuntivo/formas do infinitivo em orações subordinadas: quando a forma verbal não tem flexão (infinitivo não flexionado), a ênclise é a opção possível; quando a forma verbal tem flexão (infinitivo flexionado e futuro do subjuntivo), a próclise é escolhida. A diferença de comportamento entre os ClA3P e os de primeira e segunda fica mais uma vez evidenciada quando se mostra que os clíticos de primeira e segunda pessoa não são sensíveis a nenhum desses testes. Nunes também contrasta o comportamento dos clíticos no PB com o PE, mostrando funcionamentos distintos. Conclui dizendo que a aquisição do $\mathrm{ClA} 3 \mathrm{P}$ no PB se assemelha a um processo de aquisição de L2 e que a escola, ao atacar a ausência de concordância, faz com que se adquira um tipo de concordância não descrita nos manuais mas passa a constituir a competência linguística.

Sônia Cyrino, em O objeto nulo no português brasileiro: Sincronia e diacronia (p. 173-199), revisa a discussão, indicando que, apesar de muitas línguas permitirem o objeto nulo, o PB permite o chamado "objeto nulo anafórico", que não é possível em outras línguas românicas. Apresenta um histórico das análises feitas, mostrando que a proposta do objeto nulo do $\mathrm{PE}$ como variável não se aplica ao $\mathrm{PB}$ devido à sua possibilidade em contexto de ilha e que as análises do objeto nulo como pro também não dão conta dos dados uma vez que há contrastes de interpretação entre o objeto nulo e o pronome lexical. Cyrino assume, então, que o objeto nulo no PB é decorrente da elipse de DP, a qual a autora relaciona com traços semânticos de pessoa e animacidade, explicando por que objetos inanimados e plurais nus podem ser elididos, mas objetos animados não. A última parte do texto 
trata da diacronia do objeto nulo. Cyrino destrincha as propriedades discutidas a partir da perspectiva da mudança linguística, concluindo basicamente que a mudança é desencadeada por três fatores: perda do movimento do verbo para $T$, permitindo que o verbo numa posição mais baixa como AspP licencie o objeto nulo; perda do clítico acusativo de terceira pessoa; extensão do objeto nulo proposicional para o objeto nulo [-animado].

Maria Aparecida Torres Morais e Heloísa Maria M. Lima Salles, em Possessivos de terceira pessoa na história do português brasileiro (p. 201-223), analisam mudanças na marcação da posse de terceira pessoa no PB partindo do fato de que construções de posse externa como "O médico examinou-lhe a garganta", com clítico dativo, já soam estranhas aos brasileiros, sendo substituídas por construções de posse interna com genitivo como "O médico examinou a garganta dele". Discutem também a substituição da preposição dativa "a" pela forma inovadora "para". Examinam o percurso das formas na história do PB, evidenciando uma alteração de padrões (século XVII: predomínio das variantes com "a" e clítico dativo; século XXI: predomínio da variante com "de") e o funcionamento dessas construções no português arcaico. Em seguida, é apresentada uma análise formal para os dados empíricos. No caso das construções com posse externa, propõem a existência de um núcleo aplicativo, que pode ser alto ou baixo, fazendo com que o possuidor e o possuído sejam sintaticamente independentes; no caso das construções com posse interna, é proposta uma adjunção de um PP genitivo ao DP objeto, estabelecendo uma relação de dependência sintática. Terminam o trabalho com evidências sintático-semânticas que corroboram a análise e concluem que as mudanças linguísticas encontradas no PB podem ser um reflexo do seu processo socio-histórico de contato de línguas e aquisição de L2, que esta língua se distancia microparametricamente das demais línguas românicas e que as construções de posse externa são fósseis na gramática do PB.

Ruth E. V. Lopes, em Algumas particularidades do DP nas variedades brasileiras do português (p. 225-251), discute fenômenos relacionados com a determinação e concordância dos sintagmas determinantes no PB mostrando propriedades comuns com o PE bem como suas diferenças. Com respeito às diferenças, indica que, talvez, a maior delas seja o fato de que o PB exibe nomes contáveis singulares e plurais 
nus. Também aponta que há variação interna ao PB com relação ao fenômeno da determinação e da concordância, o que indica que não se está diante de uma única gramática. Ponderando sobre como dividirá os dados analisados, destaca, principalmente, que a oposição do fenômeno se dá entre urbano/não urbano e que é necessário isolar os nomes nus de fato dos nomes próprios e nomes com possessivo sem determinante. Com relação à concordância, são analisadas quatro localidades não urbanas diferentes e Lopes parte da assunção de que processos diacrônicos diferentes podem confluir para os mesmos resultados. Assim, mostra que, enquanto em Helvécia, Alto Xingu e Baixada Cuiabana há uma convergência para o português urbano, em Paraty-Mirim não há. Lopes analisa a realização dos determinantes antes de possessivo e nomes próprios, fazendo uma revisão diacrônica que contrasta o $\mathrm{PE}$ e o PB, para, em seguida, analisar variedades não urbanas do PB. Por fim, discute os nomes nus em duas variedades não urbanas e cruza a geografia das variedades urbanas. A autora conclui que as diferenças entre PB e PE não são apenas de frequência, mas efetivamente de gramáticas devido a mudanças na categoria funcional D.

Lorenzo Vitral e Sueli Maria Coelho, em Auxiliarização em português: Aspecto, novas formas e implicações teóricas (p. 253-282), discutem o uso de verbos auxiliares no PB. Indicam a ocorrência de um processo de gramaticalização, no qual o item lexical muda de verbo léxico para verbo auxiliar e apresentam seus três objetivos: apresentar o estado da arte; descrever simplificadamente a noção de aspecto em português; aprofundar a descrição da auxiliarização em PB trazendo formações verbais recentes. Discutem a noção de aspecto, mostrando que as línguas variam quanto à sua manifestação, e propõem três traços aspectuais ( \pm inceptivo; \pm pontual; \pm iterativo). Propõem que o verbo faz o movimento V-to-Asp-to-T no caso de formas simples e V-to-Aspto-Aux-to-T no caso de formas compostas. Discutem o surgimento de novos auxiliares no PB, especialmente de itens como "[a]garrar", "pegar", "danar, "desandar", "destapar" e "disparar", indicando que alguns já haviam surgido no século XIX mas que outros têm seus primeiros registros no século XX, evidenciando como as formas simples não são suficientes para expressar todos os matizes aspectuais. A conclusão discute por que emergem novos auxiliarias no PB e a ideia geral demonstrada é que os novos auxiliarias expressam matizes aspectuais não expressas pelos auxiliarias já disponíveis. 
Maria Cristina Figueiredo Silva, em Uma história das relativas do português brasileiro (p. 283-312), discute a história das relativas no PB, tendo como ponto de partida duas análises feitas, ambas baseadas no movimento-WH: a primeira propõe que haja dois processos de relativização (nas construções padrão, há um pronome relativo; nas construções cortadoras e lembrete, há um complementizador); a segunda propõe que no PB haja um pronome relativo em todas as estratégias, que são derivadas da relativização do tópico, a partir de construções de deslocamento à esquerda. Contudo, duas novas alternativas são apresentadas com base na proposta de alçamento, na qual o elemento relativizado seria movido de sua posição de base para SpecCP: uma em que o pronome relativo (na definição tradicional) é analisado como complementizador e outra em que é analisado como pronome relativo. Após um balanço das duas análises, Figueiredo Silva assume que "que" é um pronome relativo. Fazendo considerações diacrônicas das orações relativas, discute dados de atas de ex-escravos e de peças teatrais do século XIX e mostra que, em várias perspectivas (aquisição de L2, L1 e processamento), a análise de alçamento com pronome relativo é a mais vantajosa. Conclui examinando as relativas resumptivas de sujeito, evidenciando que são mais aceitáveis quando o antecedente é indefinido, o que a leva a fazer considerações de ordem pragmática, aspecto que pode desvendar muitas questões envolvendo as orações relativas.

Mary Kato, em Estudos sobre foco e interrogativas-Q no português brasileiro: Mudanças sintáticas e fonológicas (p. 313-335), reanalisa as mudanças pelas quais as interrogativas-Q do PB passaram fazendo uma retrospectiva de trabalhos pioneiros, que assemelhavam a história do francês com a história do PB. Kato coloca três perguntas: Como surgiram as perguntas clivadas e qual a relação delas com a mudança na ordem?; Qual a natureza das interrogativas-Q in situ no PB?; A perda da ordem VS nas interrogativas tem alguma ligação com a perda do sujeito nulo? Assumem-se três pressupostos: as línguas variam com relação ao traço [ ${ }^{ \pm}$movimento-Q]; a visão cartográfica das estruturas sintáticas; há mudanças que não são sintáticas, mas fonológicas. São apresentados dois estudos que indicaram que, até o século XIX, só havia a ordem QVS e a ordem QSV começa a surgir na segunda metade do século XIX juntamente com perguntas clivadas tanto no PB como no PE, mas que apenas no PB surge a ordem QSV. Kato assume que 
interrogativa e foco se manifestam na mesma projeção comparando o PE e o PB e mostra que, na história do português, os mesmos efeitos com as interrogativas são encontrados com as construções de foco. Analisa as interrogativas com Q in situ seguindo o japonês, em que o elemento interrogativo, nas perguntas verdadeiras se move para a posição de SpecFocP da periferia do VP, e, nas interrogativas-eco, se move para SpecFocP da periferia esquerda e toda a oração se move via movimento remanescente para SpecForceP. Propõe que o aparecimento das clivadas canônicas está relacionado com a interrogativa in situ, já que, em ambas, o movimento é para o SpecFocP baixo, e que a clivada sem cópula e sem complementizador se derivam da clivada canônica (e não da inversa) no PB. Também é feita uma discussão comparativa sobre a escrita do PE e do PB para mostrar que há variação de formas na escrita considerando seu caráter conservador. Por fim, discute a aquisição das estratégias mostrando que há uma relação entre maior frequência no input e prioridade de aquisição.

Ian Roberts, no Posfácio Da primeira à segunda viagem (p. 337351), comenta que o primeiro livro foi resultado de um curso de pósgraduação ministrado na UNICAMP em 1990, do qual resultaram os trabalhos publicados. Faz também um balanço muito importante da discussão sobre a mudança linguística no quadro geral da teoria linguística especialmente a partir do modelo de Princípios e Parâmetros, que estimulou significativamente o estudo comparativo entre as línguas. Aponta os avanços entre uma viagem e outra: apesar de os tópicos serem basicamente os mesmos, os avanços nas discussões, incluindo novas perspectivas, fenômenos e corpora além da questão crucial da variação social e regional do $\mathrm{PB}$ aliada aos contatos de língua, fazem dos estudos gramaticais sobre o PB uma importante contribuição para a teoria linguística. Roberts discute três aspectos cruciais tratados na coletânea: parâmetro do sujeito nulo; movimento do verbo; clíticos, objeto nulo e categorias vazias. Com relação ao sujeito nulo, indica que os estudos sobre o PB foram cruciais para a compreensão de que não se trata de um parâmetro binário, culminando na distinção entre línguas de sujeito nulo parcial, entre as quais o PB se encontra, e línguas de sujeito nulo consistente. No que toca ao movimento do verbo, traz a discussão sobre a relação entre concordância e posição do verbo na estrutura oracional indicando que os estudos no modelo cartográfico trouxeram grandes avanços para a questão e que o PB, mais uma vez, 
é um importante objeto de estudo, considerando que o verbo finito se localiza mais alto que em inglês porém mais baixo que em PE. Por fim, ao tratar de clíticos, objetos nulos e categorias vazias, comenta as diferenças básicas entre o PB e as demais línguas românicas, indicando que há uma relação entre objeto nulo e perda dos clíticos. O posfácio é concluído indicando que os trabalhos contidos na segunda viagem apresentaram resultados interessantes mas que ainda há muito mais para ser discutido, levando a uma terceira viagem diacrônica, a qual aguarda ansiosamente.

\section{Discussão}

A apresentação feita acima deixa claro que, embora nem todos os trabalhos se insiram no que Mattos e Silva $(1988,1999)$ chamou de Linguística Histórica Stricto Sensu, dado que nem todos fazem descrições diacrônicas dos processos de mudança linguística, a obra claramente se insere no quadro do que a autora chamou de Linguística Histórica Lato Sensu: examina dados datados e localizados, está interessada em explicar propriedades do PB atual que o diferenciam de outras épocas e variedades do português.

A obra tem, pelo menos, quatro aspectos muito positivos:

A) Discussão sobre a heterogeneidade do PB atual. Como sinalizado por trabalhos da coletânea, o fato de o PB compartilhar, de forma geral, um grande conjunto de propriedades não significa que diacronicamente tenham se originado nem se desenvolvido da mesma maneira ${ }^{5}$.

B) Discussão sobre as origens do PB. Vários capítulos mostram que muitas das estruturas sintáticas encontradas no PB são compartilhadas com outras variedades africanas do português mas não com o PE. Esse fato sugere fortemente que as línguas africanas tenham desempenhado um papel fundamental na constituição do PB uma vez que os africanos escravizados aprendiam o português como segunda língua sem qualquer tipo de instrução formal quando chegavam ao Brasil, embora também seja considerado que nem todas as mudanças sejam decorrentes do contato linguístico.

5. Conferir o interessante debate feito por Pagotto (2018) sobre a constituição do português brasileiro pensada a partir das relações econômicas desenvolvidas no país desde o início de sua colonização, que podem ter condicionado, de diversas maneiras, as relações sociais e, portanto, as configurações linguísticas por todo o território. 
C) A relação indissociável entre Linguística Teórica e Linguística Histórica (Mattos e Silva, 1988, 1999). Todos os trabalhos apresentados têm um sólido arcabouço teórico para análise do PB e do qual o PB é fonte de informação. A questão da propriedade do sujeito nulo foi determinante no esclarecimento de noções como "parâmetros", o que provocou alterações teóricas significativas, como a natureza da posição SpecIP/TP, que, desde a discussão sobre a caracterização das línguas V2, já fora questionada quanto a ser exclusivamente A ou A'.

D) A relação entre sintaxe e semântica. Com o avanço das pesquisas sobre o $\mathrm{PB}$, diversos dos capítulos da coletânea podem fazer importantes observações sobre o papel da relação entre sintaxe e semântica na mudança gramatical. No âmbito da linguistica formal, essas reflexões podem contribuir para a compreensão de como o sistema computacional codifica as informações semânticas e quais podem ser os limites e restrições encontrados nessa relação.

A agenda de pesquisa sobre a história gramatical do PB se insere, desde os seus primeiros momentos, refletida em Roberts e Kato (1993), no contexto maior do programa comparativista no quadro gerativista elaborado por Chomsky (1981) e Lightfoot (1991), que propõe que a mudança linguística (a mudança gramatical, mais precisamente) ocorre devido a uma fixação de parâmetros divergente entre as gerações.

Os trabalhos de Kroch $(1989 ; 2001)$ procuram explicar como a mudança paramétrica acontece no mundo social da língua, onde se observam variação linguística e uma série de outros fenômenos relacionados (como contato entre línguas e variedades de línguas diferentes) com o uso da língua nas mais diversas comunidades linguísticas. Esses pressupostos teóricos sedimentaram a base das investigações sobre a história gramatical do $\mathrm{PB}$, que produziram muito bons resultados nesses 30 anos desde que Tarallo e Kato (1989) lançaram seu manifesto, assim como, consequentemente, fizeram surgir novas perguntas, que mantêm a agenda de pesquisa em Linguistica Histórica numa perspectiva formalista sempre atualizada e pujante aguardando por muitas viagens diacrônicas. 


\section{Referências}

CHOMSKY, Noam. 1981. Lectures on Government and Binding. Dordrecht: Foris.

KROCH, Anthony. 2001. Syntactic Change. In: BALTIN, Mark; COLLINS, Chris (orgs.). The Handbook of Contemporary Syntactic Theory. Oxford: Blackwell. p. 699-730.

1989. Reflexes of Grammar in Patterns of Language Change, Language Variation and Change, v. 1, p. 199-244.

LIGHTFOOT, David. 1991 How to set parameters: Arguments from Language Change. Cambridge, Massachucetts: The MIT Press.

MATTOS E SILVA, Rosa Virgínia. 1999. Orientações atuais da linguistica histórica brasileira, D.E.L.T.A., v. 5, número especial, p. 147-166.

. 1988. Fluxo e Refluxo: uma retrospectiva da lingüística histórica no Brasil, D.E.L.T.A., v. 4, número 1, p. 85-113.

PAGOTTO, Emílio. 2018. Ebulição e sedentarização linguística o lugar da economia de subsistência na formação do português brasileiro, Diadorim, v. 20, n. especial, p.53-63.

TARALLO, Fernando; KATO, Mary. 1989. Harmonia trans-sistêmica: variação intra- e inter-lingüística, Preedição, 6, p. 1-41.

Recebido em: 16/06/2019

Aprovado em: 05/03/2020 